\title{
EL MUNICIPIO DE ZALDUONDO Y LAS PARZONERIAS ALAVESAS Y GUIPUZCONAS
}

\author{
POR \\ Jesus $M^{a}$ Garayo URRUela
}

El municipio de Zalduondo junto con los nueve pueblos del municipio de Aspárrena, a saber, Amézaga, Andoín, Araya, Arriola, Eguino, Gordoa, Ibarguren, Ilárduya, Urabain y Zalduondo, todos ellos pueblos de la Llanada Alavesa en su vertiente NE y en los confines que separan Alava, Guipúzcoa y Navarra, integraron la Hermandad de Aspárrena desde su formación en torno a la década de los sesenta del siglo XV hasta su disolución en el XIX.

Las Parzonerias (1) se asimilan a las comunidades de montes, formadas por pueblos y municipios, con las que coinciden en naturaleza jurídica, organización y problemática. Parzoneria es el nombre con el que se conoce a las comunidades de montes en un área determinada del País Vasco, en concreto en las Sierras de Encia y, su opuesta, la

(1) Sobre las Parzonerias, la bibliografia disponible tiende tanto a aspectos de interpretación (T. LEFEBVRE, Les modes de vie dans les Pyrenées Atlantiques Orientales. Paris, Librairie Armand Colin, 1933; J.M. BARANDIARAN, "Aspectos sociográficos de la Población del Pirineo Vasco", Eusko-Jakintza, VIII (1953-1959), 3-26; J. CARO BAROJA, Los vascos. Madrid, Ismo, 1975, 4a edición; M. LECUONA, "Instituciones vascas" en Euskaldunak. La etnia vasca. Zarauz, Itxaropena, 1978, I, 33-64; A. URZAINQUI, Comunidades de montes en Guipúzcoa: Las Parzonerias. Tesis doctoral: Pamplona, Facultad de Filosofia y Letras de la Universidad de Navarra, 1989, trabajo publicado en los Cuadernos Universitarios Mundaiz San Sebastian, 1991) como recopilaciones históricas (P. GOROSABEL, Noticias de las cosas memorables de Guipúzcoa. Bilbao, La Gran Enciclopedia Vasca, 1972, 3 vols.; F. GRANDES, Cosas de Salvatierra. Vitoria, 1939. La parzoneria más estudiada es sin duda la Parzonería General de Guipúzcoa y Alava (L. MAROUES CARBO, "La Parzoneria General de Guipúzcoa y Alava", Revista de Estudios de la Vida Local, no 65 (1952), 700-709; A. EZCURDIA y J.I. LASA, "EI pastoreo en la zona de Urbia-Oltza”, Anuario de Eusko-Folklore, XV (1955) 161-166; I. ZUMALDE, "Oñate en la Parzonería de Olza y Urbia", Anuario de Eusko-Folklore XV (1955), 145-153; J.M" AYCART, "Aguirre Miramon y la Parzoneria General de Guipúzcoa y Alava", Boletín de Estudios Históricos sobre San Sebastián, II, no 16-17 (1982-1983), 998-1005; J. ZUFIAURRE GOYA, "Parzonerías", en: Mendiak. Montes de Euskalherria. Naturaleza y huella humana. Donosti, Etor. 1983, V, 56-57; A. URZAINQUI MIQUELEIZ "Parzoneria de Guipúzcoa y Alava. Consideraciones en torno a su división en porciones", Lurralde, $n$ ㅇ 11 (1988), 453-458). Las Parzonerias alavesas de Encia, Iturrieta y Encia Arriba han sido estudiadas por J.Ma Garayo y el grupo EKAIN, permaneciendo estos trabajos inéditos salvo algunos aspectos puntuales (J.M" GARAYO URRUELA; "Roturaciones en la Sierra de Encia", Lurralde, $n^{2} 12$ (1989), 141-160). 
de Alzania, Olza y Urbia, que hacen de divisorias naturales de las provincias de Alava, Guipúzcoa y Navarra (2).

Las entidades locales, que encabezan la propiedad de montes bajo la denominación de Parzonerías, son diez, siendo una de ellas la Hermandad de Aspárrena: Segura, Cegama, Cerain e Idiazabal (en la comarca de Goierri), por parte guipuzcoana, y Salvatierra y las Hermandades de Aspárrena y San Millán (en la Llanada), Valle de Arana y pueblos de Onraita y Roitegui (en la Montaña), por parte alavesa.

La agregación de Zalduondo a la Hermandad de Aspárrena fue la fórmula que, en la segunda mitad del XV, se consideró idónea para, por un lado, mantener la personalidad propia y diferenciada de Zalduondo, surgida a partir de su pertenencia al señorío de la Casa de Oñate, estableciendo a su vez, un paraguas protector para los vecinos infanzones $y$, por otro, para, conciliando población y recursos económicos, constituir, en relación a cuestiones como los asuntos provinciales o la posesión y uso de los montes comunales, estructuras politico administrativas con la dimensión, la entidad y el mayor dinamismo posible (3).

A finales del XVIII y entrado el XIX, Zalduondo empezó a valorar como costosa la agregación a la Hermandad de Aspárrena. Por esas fechas, diluídas las consecuencias políticas y sociales del señorío, desaparecido en 1812 a raíz de los decretos abolicionistas de las Cortes de Cádiz, la pertenencia a la Hermandad de Aspárrena le representaba "gastos superpuestos sin que, a cambio, pudiera obtener algo distinto a lo que alcanzaba por sí misma. En este contexto, la normativa liberal décimonónica en materia municipal, contraria a las jurisdicciones compartidas y paralelas, marcó un punto sin retorno para una vinculación entre dos entidades que se encontraba prácticamente muerta tras haber atravesado por momentos difíciles y borrascosos en las décadas finales del XVIII e iniciales del XIX.

La desintegración de la Hermandad de Aspárrena se produjo a instancia de Zalduondo en 1842 sin que, con la individualización municipal, se procediese a la separación de los bienes patrimoniales de la Hermandad. La comunidad de estos bienes y el provecho que la Hermandad reportaba en cuestiones fiscales de ámbito provincial, fueron factores que provocaron un período de transición en el que,

(2) J.Ma GaRAYO URRUela, "Las Parzonerias del País Vasco", Sustrai, no 19 (1990), 54-56.

(3) El estudio de la integración de Zalduondo a la Hermandád de Aspárrena asi como su posterior evolución hasta su desintegración ha sido emprendido en un trabajo inédito por J.Ma GARAYO URRUELA (La integración de Zalduondo en la Hermandad de Aspárrena: condiciones, ventajas e inconvenientes. Arcaute, Granja Modelo, 1986). 
unos años, Zalduondo estaba unida a la Hermandad $y$, en otros no. Separada la villa de la Hermandad en 1842, unida en 1851 y desagregada en 1859, el proceso de división municipal puede considerarse cerrado en 1881 con la separación en el encabezado del impuesto provincial de la sisa.

Los bienes patrimoniales de la Hermandad de Aspárrena estaban constituídos en el momento de la separación municipal por la Casa Consistorial de la Hermandad y las participaciones en los montes de las Parzonerías de Ubarrundia (1/2) y las Generales de Guipúzcoa y Alava $(27,1 / 2)$ y de Encía (1/8).

La desaparición de la Hermandad de Aspárrena supuso, para el municipio de Zalduondo, la ruptura de canales de representación y administración dentro de las Juntas de las Parzonerías tal como había venido sucediendo hasta mediados del XIX. Las páginas siguientes se dedican a estudiar las consecuencias derivadas para Zalduondo respecto a la representación y gestión de los bienes patrimoniales de la Hermandad de Aspárrena una vez disuelta ésta. Los aspectos desarrollados son los siguientes: la representación en las Juntas de Parzonerias, la venta, por parte de Zalduondo, de los derechos en el arbolado de los montes parzoneros y de la parte sobre la casa de la Hermandad, la rendición anual de cuentas a causa de los recursos procomunales y la cuota de participación en los mismos.

En fin, el núcleo del trabajo se centra en el análisis de las repercusiones organizativas e institucionales, derivadas por la evolución de un ente territorial, que, en vez de ser titular dominical de una o varias fincas forestales en exclusiva, posee participaciones en montes compartidos con otros entes territoriales.

\section{PARTICIPACION DE ZALDUONDO EN LAS JUNTAS DE LAS PAR- ZONERIAS}

Dentro de la primitiva merindad de Eguilaz, espacio comarcal homogéneo o poco diferenciado existente ya para el siglo XI, se fue produciendo entre los siglos XII al XV, una estructuración del territorio, aglutinándose $\mathrm{y}$ jerarquizándose en los siguientes polos de referencia: a) Salvatierra y sus aldeas, sobre las que ejercía un señorío colectivo, b) las Juntas de San Millán y Aspárrena y c) Zalduondo, señorio jurisdiccional de los Guevara de Oñate.

La evolución territorial experimentada no supuso obstáculo alguno para que los vecindarios de las diversas entidades político-administrativas, en las que se desgajó la primitiva merindad de Eguilaz, siguieran disfrutando de los productos y mantuvieran sus derechos en las parzonerías. 
En la firma de la escritura de concordia, ocurrida en la cueva de San Adrián el 16 de noviembre de 1430, con vistas a resolver cuestiones aparecidas entre guipuzcoanos y alaveses por el uso y aprovechamiento de los montes de Alzania, junto a los apoderados de Segura, Cegama, Idiazabal y Cerain, parcioneros guipuzcoanos derechohabientes, aparecen entre los alaveses, los representantes de Salvatierra, Hermandad de Eguilaz y Zalduondo (4). En una fecha, en la que la Hermandad de Eguilaz no se había desdoblado en las Juntas de San Millán y Aspárrena, Zalduondo, a través de una persona, que reunía la condición de alcalde de Guevara, de la Hermandad de Eguilaz y de Zalduondo, participó en la firma del documento que se considera el constitutivo de la Parzonería de los montes de Alzania, Olza y Urbía.

Producida la integración de Zalduondo en la Hermandad de Aspárrena, ambas formaron un cuerpo común en relación al uso y derechos en Encía, en Ubarrundia y en Alzania, Olza y Urbía. La asociación de Zalduondo a la Hermandad de Aspárrena, garantizando la presencia de ambas en las respectivas Juntas de Parzonerías, supuso un abaratamiento de los costos, que dicha presencia les hubiera significado en el caso de que cada una de las entidades hubiera decidido participar por separado en la vida y organización institucional.

Del siglo XVII, concretamente, de su primera mitad, datan los documentos, por los que parece reflejarse un reconocimiento de Zalduondo en cuanto miembro de la Parzonería de Guipúzcoa y Alava. Esta situación surgió en un momento en que diferentes entes parzoneros guipuzcoanos recuperaron su personalidad propia.

Distantes y resueltos los motivos, por los que los pueblos de Cegama, Cerain e Idiazabal se anexionaron a Segura, aquéllos en un movimiento, que afectó a los lugares integrados en las villas de Tolosa y Villafranca, lograron segregarse hacia 1615. El Ldo. Hernando de Ribera, juez ejecutor encargado de dar posesión de la jurisdicción a los lugares separados de las villas mencionadas, al llevar a cabo esta operación en los montes de Alzania, Olza y Urbía, citó entre los alaveses, además de Salvatierra y Hermandades de San Millán y Aspárrena, a la villa de Zalduondo. En el escrito de convocatoria de 22 de noviembre de 1615, se considera a Zalduondo y sus vecinos "...como a personas interesadas que tienen jurisdicción... de los montes comuneros de Urbía, Olza y Alzania, San Adrián y St. Espiritus con los aprovechamientos de cortar leña, madera, traer carbón y pacer las hierbas y beber las aguas y todos los demás aprovechamientos que tienen los de la parzonería de esta provincia de Alava y Guipúzcoa" (5).

(4) P.GOROSABEL, Noticias de las cosas memorables de Guipúzcoa. Bilbao, La Gran Enciclopedia Vasca, 1972, 11, 487.

(5) A.M.Z., 68 y A.M.S.M., $28,4$. 
A la sesión de la Parzonería, celebrada en la cueva de San Adrián el 11 de noviembre de 1655, acudió, en representación de Zalduondo, Manuel Arriarán, Caballero del Hábito de Alcántara. La admisión de Zalduondo en la Junta de la Parzoneria de Guipúzcoa y Alava fue apoyada por los pueblos guipuzcoanos y por la Hermandad y Junta de Aspárrena. Sin embargo, Salvatierra y San Millán se opusieron a ello. La diferente posición de unos y otros, radicaba en la diferente valoración, que daban a actas y documentos, que no se especifican pero que, posiblemente, consisten en la Concordia de 1430 y las actas de posesión de 1616.

La relación institucional de Zalduondo con la Parzonería de Guipúzcoa y Alava es totalmente distinta en el documento de 1616 que en el de 1655 . Mientras el primero refleja una situación consolidada y sin retorno, el segundo manifiesta la modificación de un estado de cosas secular, caracterizado por la asociación de Zalduondo en la Hermandad de Aspárrena para determinados fines particulares, de la que, entonces, por motivos ignorados, Zalduondo pretendió separarse.

Por los datos anteriores y posteriores, de que se disponen, se puede afirmar que, en el XVII, salvo circunstancias puntuales, Zalduondo no llegó a poseer personalidad propia en las Juntas de las Parzonerias de forma continuada y estable. Zalduondo retomó este objetivo en torno a la segunda mitad del siglo XIX con la separación de la Hermandad de Aspárrena.

En la sesión de 4 de noviembre de 1842, la Diputación autorizó a Zalduondo para, a su costa, nombrar un comisionado que, en unión del que eligiese el ayuntamiento de Aspárrena, asistiese a las Juntas de las Parzonerías, participando de este modo en la toma de decisiones y acuerdos sobre asuntos de interés común a las mismas (6).

Apoyándose en el acuerdo de 4 de noviembre de 1842, Zalduondo acudió a la reunión de la Junta que la Parzonería General de Encia celebró el 14 de diciembre de 1851, manifestando "que se consideraba con acción a concurrir a esta Junta y demás iguales actas que en lo sucesivo se celebrasen". En aquellas fechas, Zalduondo se encontraba de nuevo integrado en la Hermandad, por lo que los representantes de la misma en la Junta de la Parzonería General de Encia se opusieron (7).

(6) A.H.P.A., Actas, 76.

(7) Los argumentos, en los que la Hermandad de Aspárrena se apoyaba para negar la representación a Zalduondo, están contenidos en el acta de 14 de diciembre de 1851: "...si la Diputación Provincial en mil ochocientos cuarenta y dos accedió a los deseos de la villa de Zalduondo, fue sin oir ni dar conocimiento de ello a la Junta General de la Parzoneria y porque en aquella época se separó del cuerpo de la Hermandad a que pertenece, figurando una cuarta parte de encabezado para los productos y gastos que ocurriesen..." (A.M.S., Actas Parzoneria Encía). 
Aparte de su inclusión en la Hermandad, en la decisión de la Junta de la Parzonería General de no reconocer personalidad propia en la misma al municipio de Zalduondo, intervino también el temor a que los pueblos integrados en los Ayuntamientos de Aspárrena y de San Millán secundasen la acción de Zalduondo (8). La comparación y asimilación de Zalduondo con el resto de los pueblos integrantes de los municipios de Aspárrena y San Millán no resulta certera. Zalduondo formaba municipio aparte mientras que el resto de los pueblos, solamente, juntos pero no por separado, alcanzaban tal nivel de representación político-administrativa.

Desintegrada la Hermandad de Aspárrena y subdividida en los municipios de Aspárrena y Zalduondo, la participación de éste como un miembro más en las Juntas de las Parzonerías, en el horizonte de un uso y dominio, que arrancaban de siglos atrás, no debía plantear mayores dificultades que las que, en su tiempo, aparecieron con la evolución de la organización territorial de la comarca, es decir, de la antigua merindad de Eguilaz que, desgajada Salvatierra, se desdobló en las Hermandades de Aspárrena y San Millán, dándose una sucesión y ampliación de entidades derechohabientes a los montes de las Parzonerias. El reconocimiento de personalidad propia de Zalduondo ante las Juntas de Parzonería no venía a ser sino un refrendo y un reflejo de la evolución en la organización territorial experimentada en la primitiva merindad de Eguilaz.

Zalduondo volvió a plantear nuevamente la cuestión en 1895, solicitando a la Diputación Provincial que, por quien correspondiese, se ordenase a los presidentes de las Parzonerías de Encía, de Ubarrundia y de Guipúzcoa y Alava para que, en lo sucesivo, le convocasen a sus Juntas "... con el fin de que esta villa nombre un comisionado y pueda de esta manera saber sus decisiones y acuerdos".

Aspárrena y la Junta de la Parzonería General de Encia se manifestaron contrarios a las pretensiones del municipio de Zalduondo, recordándoles anteriores intentos fallidos por la misma cuestión y haciéndoles ver que, al depender de estos asuntos del Ayuntamiento de Aspárrena, "... su representación en las Juntas de Parzonería sería la de unos meros espectadores, como puede serle cualquier vecino de los pueblos copartícipes de aquella". La Comisión Provincial de Alava, por

(8) El acta de 14 de diciembre de 1851 decia: "hallándose enclavada (la villa) en la referida Hermandad, formando un solo cuerpo para todos los asuntos relativos a dichos intereses procomunales, y otros varios, sería una novedad hasta ahora desconocida dar entrada en tales sesiones a un pueblo aislado, pues que esto podria dar lugar a que se desconociese en San Millán y Aspárrena el derecho indisputable de nombrar su respectivo Ayuntamiento sus comisionados representantes y que esto se intentase ejecutar por pueblos" (A.M.S. Actas Parzoneria Encia). 
el decreto de 20 de febrero de 1895, contestó al municipio de Zalduondo, que remitiese la solicitud de convocatoria a reuniones a los presidentes de las Parzonerías los cuales "... en vista de los documentos que existan en el archivo de la misma podrán contestarle si tienen obligación de hacerlo o no" (9).

En 1895, como en 1851, Zalduondo no logró sus objetivos en relación al reconocimiento de personalidad ante las Juntas de las Parzonerías. A pesar de ello, Zalduondo se mantuvo en su reclamación y el reconocimiento tardó en llegar una década más tarde, sucediendo en 1906 y afectando solamente a la Parzonería General de Encía pero no a la Parzonería General de Guipúzcoa y Alava. En la sesión de 17 de diciembre de 1906, ante la solicitud que, por este motivo, le dirigió Zalduondo, la Junta acordó reconocer con personalidad jurídica ante la Parzonería al municipio de Zalduondo "que usufructúa una octava parte con Aspárrena" (10) .

El acuerdo anterior venía precedido de una lucha por parte de Zalduondo para ser incluido en los artículos $^{\circ}$ y 3 , aquellos, que, en las Ordenanzas de la Parzonería General de Encía (1907) (11), se referían a los miembros, derechos de propiedad y reparto de beneficios, lo que consiguió en su texto final y culminó en la citación para asistir a la Junta de la Parzonería del 20 de junio de 1908 (12). Con esto, se hacía realidad, al menos, parcialmente, el secular objetivo de Zalduondo, reconociéndosele su estado de municipio, idéntico al del resto de titulares condueños de Parzonería, y personándose en las reuniones de sus juntas.

Zalduondo vino asistiendo a las sesiones celebradas por la Junta de la Parzonería General de Encia a lo largo del período de 1908-1920 (13), dejando de asistir ininterrumpidamente a partir del año 1922 y

(9) A.M.Z.

(10) A.M.S., Actas Parzoneria Encía.

(11) Las Ordenanzas de la Parzoneria General de Encia, en su art. 10, dicen: "La Parzonería General de Encía, es una comunidad compuesta de los Ayuntamientos de Salvatierra, Aspárrena, Zalduondo y San Millán y pueblos de San Vicente Arana, Contrasta, Alda, Ullivarri Arana, Onraita y Rotigui, celebrando sus sesiones bajo la presidencia del Sr. Alcalde de Salvatierra o de quien le represente".

(12) A.M.Z., Actas de 16 de septiembre de 1906, de 17 de marzo de 1907 y 18 de junio de 1908.

(13) Mirando las actas de la Junta de la Parzoneria General de Encia, se ha podido comprobar la asistencia de Zalduondo a las reuniones de 20 de junio y 21 de diciembre de 1908, a la de 18 de diciembre de 1910, a la de 23 de diciembre de 1912, a la de 22 de diciembre de 1913, a las de 16 de mayo, 25 de septiembre y 21 de diciembre de 1914, a la de 12 de mayo de 1915, a las de 18 de mayo, 5 de junio y 17 de diciembre de 1917 y a la del 7 de junio de 1920. Sin embargo no asistió a las reuniones de 26 de junio y 20 de diciembre de 1909, a la de 19 de diciembre de 1910 y, de forma interrumpida, a las reuniones posteriores a la celebrada el 27 de junio de 1922 (A.M.S., Actas Parzoneria Encía). 
omitiéndosele de forma epecífica en cuanto miembro de la comunidad en el art. $1^{\circ}$ del Reglamento de la Parzonería General de Encía, aprobado en la sesión celebrada por la Junta de la misma el 28 de junio de 1922.

En las actas municipales de Zalduondo, no se encuentra aclaración alguna a los hechos referidos (14), aunque se ha verificado que, en la sesión de 19 de abril de 1925, los corporativos acordaron solicitar del Ayuntamiento de Aspárrena la liquidación de las cuentas por la parte que la pudiera corresponder por los aprovechamientos en la Sierra de Encía, Ubarrundia y Olza (15), lo que invita a pensar que, desde unos años atrás, Zalduondo habia delegado en el Ayuntamiento de Aspárrena la representación de sus intereses en la Junta de la Parzonería General de Encía (16).

Para cubrir el vacío institucional creado, Zalduondo desarrolló una serie de iniciativas pero, una vez alcanzadas, como sucedió con el reconocimiento de personalidad jurídica en la Junta por parte de la Parzonería General de Encia, se comportó de forma vacilante e inestable.

De este modo, por razones probablemente económicas, por la rebaja, que ello representaba en los gastos y dietas a las sesiones de la Junta, Zalduondo, voluntariamente, renunció al reconocimiento de personalidad logrado en la Junta de la Parzonería General de Encía.

En lo sucesivo, el reconocimiento de personalidad ante las Juntas de las Parzonerías dejó de ser reivindicado por Zalduondo. Solamente, tras la implantación de los ayuntamientos democráticos, la presencia o no, por sí misma, ha vuelto a plantearse y debatirse entre los miembros de la Corporación municipal, surgiendo de nuevo una

(14) En las actas del municipio de Zalduondo, la última referencia a la presencia de Zalduondo en las sesiones de la Junta de la Parzoneria de Encia corresponde a la celebrada el 4 de junio de 1920, en la que se leyó la citación convocatoria a la reunión de 7 de junio de 1920, última sesión de la Parzonería de Encia, a la que se sabe asistió Zalduondo.

(15) A.M.Z., Acta de 19 de abril de 1925.

(16) La delegación en el Ayuntamiento de Aspárrena por parte de Zalduondo para representarle en la Junta de la Parzonería General de Encía viene corroborada por informaciones orales proporcionadas por personas de edad, quienes dicen recordar que viene haciéndose desde cincuenta años o más. En las actas municipales, se ha encontrado una referencia documental de delegación de repreșentación en Aspárrena por parte de Zalduondo, que puede ayudar a explicar el comportamiento de la villa. La referencia corresponde al acta de 19 de diciembre de 1884 . Se debatia el nombramiento de representantes encargados de gestionar, en colaboración de los designados por el resto de entidades parzoneras, la excepción de la amortización de los montes de la Parzonería General de Guipúzcoa y Alava. Los municipios acordaron delegar su representación en la Comisión del Ayuntamiento de Aspárrena “... teniendo presente de que prestarán el mismo interés para ellos como para nosotros ..." (A.M.Z., Actas). 
cuestión que, con el paso de las generaciones, empieza a ser recurrente.

En cualquier caso, pocos años después de haber logrado el reconocimiento de personalidad en la Junta de la Parzoneria General de Encía, sucedió un hecho que, lógicamente, tuvo su peso en la decisión de renunciar a su participación directa en la vida y marcha de la Junta, la venta de los derechos de arbolado, que le correspondian en los montes de Alzania, Olza, Encía y Ubarrundia, aspecto al que se hace referencia en el apartado tercero de este trabajo.

\section{CUOTA DE PARTICIPACION EN LOS INGRESOS PATRIMONIALES}

El convenio de 9 de mayo de 1765, que la Hermandad de Aspárrena y Zalduondo firmaron con vistas a poner fin a diversos pleitos que tenían entablados entre sí, habia fijado como criterio de reparto de beneficios provenientes de la explotación de los bienes patrimoniales de la Hermandad el de la población. En 1842, cuando Zalduondo se separó por primera vez de la Hermandad, se estableció una cantidad fija, la cuarta parte.

Las actas de rendición anual de cuentas de 1869 a 1883, en las que el criterio aplicado para reparto de beneficios fue el número de pagadores, número invariable en todos esos años (17), demuestran la vigencia del criterio de población, pues ya, no era el cuarto establecido en 1842 (18) sino un $18,6 \%$, pero, a la vez, la cuota fue estable en un período determinado de años (19).

En las cuentas de los años 1885-1895, liquidadas en 1899, nuevamente, se cambió el porcentaje de participación en los ingresos netos provenientes de los recursos procomunales a la Hermandad: en vez del $18,6 \%$, se aplicó el $10 \%$, cuota refrendada por la cláusula cuarta de la escritura notarial de 11 de diciembre de 1909. Esta, dejando sin valor la, a su vez, cuarta del convenio de 9 de mayo de 1765, que hacía referencia a la población como criterio a tener en cuenta en las liquidaciones por ingresos de bienes patrimoniales de Hermandad, estipuló por mutuo acuerdo de las partes que "... de hoy

(17) Zalduondo figuraba con 66 pagadores dentro de los 354, que sumaban los diez pueblos de la Hermandad.

(18) La rendición de cuentas de 1862 es la última ocasión que se ha podido comprobar documentalmente la aplicación a Zalduondo de una liquidación sobre la cuarta parte (A.H.P.A., D. 789/6).

(19) En los años de 1869 a 1883, el porcentaje de los habitantes de Zalduondo en relación al conjunto de la Hermandad oscilaria entre el $18,02 \%$ de 1871 , el $17,02 \%$ de 1877 , el $16,75 \%$ de 1884 y el $16,79 \%$ de 1887 . En cambio, en todo este periodo, se aplicó una cuota de participación de ingresos que se acerca al porcentaje de población de 1871 y que, a pesar de la variabilidad demográfica demostrada, se mantuvo invariable. 
en adelante percibirá el ayuntamiento de Zalduondo el diez por ciento de los beneficios líquidos que al ayuntamiento de Aspárrena corresponda por concepto de aprovechamiento de pastos..." en los montes de Alzania, Olza y Urbía, de Encía y de Ubarrundia.

A la vista de la evolución del número de habitantes de Zalduondo y de la Hermandad de Aspárrena, que resulta de la suma de los existentes en los municipios de Aspárrena y Zalduondo, se puede comprobar la aplicación del criterio de población en las cuotas de participación en los ingresos patrimoniales, ajustándolo a un porcentaje fijo y estable a lo largo de un determinado período temporal. Así, se hizo en 1869-1883, en 1885-1895, y se consignó para lo sucesivo en 1909 .

Se desconocen los criterios aplicados en la liquidación de las cuentas de los años 1926-27 y en las de 1928. Probablemente, sería el convenido en 1909. El detalle de liquidación de cuentas presentado en 1952 por Aspárrena se halla redactado en una forma poco clara pero de su atenta lectura, se concluye que, si bien parece aceptarse el porcentaje del $10 \%$, a la hora de aplicarse, por hacerse, por razones que no se especifican, sobre la mitad de los ingresos netos obtenidos de los montes de la Parzonería General de Encía, Zalduondo veía rebajada su participación al 5\%. De la explotación de los montes de la Parzonería General de Guipúzcoa y Alava, no se generaron ingresos sino gastos pero, al distribuirse los mismos, se hacía contribuir a Zalduondo con el $50 \%$ sobre el total de los mismos. Ante tales pretensiones, Zalduondo no podía dejar de protestar y, asi lo hizo como se puede comprobar por las actas (20).

De todos modos, el detalle de las cuentas de 1952, transcurridos más de cuarenta años del convenio de 1909, introduce variaciones a lo entonces establecido, debidas no tanto a un interés de Aspárrena por volver a situaciones anteriores, que le resultasen más ventajosas, pues todavía, hasta 1960, Zalduondo aportó el $10 \%$ de los efectivos demográficos totales de la Hermandad, sino a una maliciosa y coyuntural interpretación sin antecedentes ni cobertura documental.

Conocida la evolución demográfica desde 1909 hasta nuestros dias, el contenido de la cláusula cuarta ha beneficiado a Zalduondo pues de haberse proseguido con el criterio acordado en 1765 , en vez del $10 \%$, actualmente, le hubiera correspondido percibir una cuota igual o inferior al $7 \%$ de los beneficios liquidos.

(20) A.M.Z., Acta de 3 de septiembre de 1953. Al no recibirse contestación, Zalduondo insistió en el tema pidiendo aclaraciones al municipio de Aspárrena en la sesión de 30 de diciembre de 1953. Frases como "aclaración de cuentas de Parzonería" $y$ "asunto pendiente de Parzoneria con Aspárrena" aparecen en las actas de las sesiones municipales de 3 de julio de 1960 y 9 de octubre de 1962, lo que introduce la sospecha que el asunto seguia sin cerrarse por no estar conforme Zalduondo con la liquidación presentada. 
Hermandad de Aspárrena, 1797-1981: número de habitantes con distinción de los de Zalduendo.

$\begin{array}{cccc}\text { Años } & \text { Adad. Aspárrena } & \begin{array}{c}\text { B } \\ \text { Zalduondo }\end{array} & A / B \\ 1797 & 1.055 & - & - \\ 1821 & 954 & - & - \\ 1829 & 1.303 & - & - \\ 1843 & 1.226 & 273 & 22,27 \\ 1857 & 2.194 & 397 & 18,09 \\ 1860 & 1.945 & 368 & 18,92 \\ 1864 & 2.194 & 397 & 18,09 \\ 1871 & 2.137 & 385 & 18,02 \\ 1877 & 1.992 & 339 & 17,02 \\ 1884 & 1.886 & 316 & 16,75 \\ 1887 & 1.942 & 326 & 16,79 \\ 1894 & 1.967 & 273 & 13,87 \\ 1897 & 2.247 & 242 & 10,77 \\ 1900 & 2.392 & 252 & 10,54 \\ 1910 & 2.428 & 296 & 12,19 \\ 1920 & 2.544 & 271 & 10,65 \\ 1930 & 2.445 & 282 & 11,53 \\ 1940 & 2.153 & 247 & 11,47 \\ 1950 & 2.121 & 225 & 10,61 \\ 1960 & 2.258 & 242 & 10,72 \\ 1970 & 2.211 & 195 & 8,82 \\ 1975 & 1.894 & 117 & 6,18 \\ 1981 & 1.813 & 128 & 7,06 \\ 1986 & 1.557 & 119 & 7,64\end{array}$

Fuentes:

A.H.P.A., D-48, D-26/2, D-36/1, D-4.818/2, D. 1413/1, D.1251/1, D.182/1, D.1639/1, D.473/3 y D.1255/1.

Diputación Foral de Alava, Padrones 1884, 1975 y 1986.

INE: Censos de Población (1900-1970)

Gobierno Vasco: Censo de Población (1981). 


\section{VENTA DE LOS DERECHOS DE ZALDUONDO EN EL ARBOLADO DE LOS MONTES PARZONEROS Y EN LA CASA DE LA HERMANDAD.}

Hacia finales del XIX, en 1895, Zalduondo fracasadas sus gestiones de fusión con el municipio de Aspárrena (21), solicitó a la Diputación de Alava la división de la porción de arbolado, que la Hermandad disponía en los montes de Encía. Por escritura, que Pedro de Ibarreta, notario de Salvatierra, levantó sobre la división de vuelo en la Parzoneria General de Encia, las Hermandades de Aspárrena y San Millán recibieron en 1859 una de las tres porciones, en las que se dividió el arbolado de Encía (22). La petición cursada por Zalduondo en 1895, una vez deslindada en 1862 la parte de la Hermandad de Aspárrena a la de San Millán (23), buscaba que se le asignase la parte correspondiente en el arbolado asignado a la Hermandad de Aspárrena en los montes de Encía para, de este modo, poder disponer privativamente de la misma (24).

Aspárrena, aunque era contraria a la misma por las dificultades originadas al tener que distribuir entre cada uno de los diez pueblos congozantes un arbolado reducido y clareado, manifestó no tener inconveniente alguno al respecto siempre que lo solicitase la mayoría de los vecindarios de los municipios de Aspárrena y Zalduondo. Esto no parece que sucedió, lo que llevó a Zalduondo a plantearse la salida de la venta de su participación en el arbolado de los montes de las Parzonerias y que se llevó a la práctica quince años después.

Dividida la antigua Hermandad en dos municipios, la casa consistorial de la misma pasó a ser la sede de uno de ellos, el de Aspárrena, en el que se integraron los nueve pueblos restantes, excluído Zalduondo. Desde 1894 (25), la villa estuvo interesada en tasar el valor de la misma y recibir la parte correspondiente de un bien que, para ella, ya no tenia ningún uso funcional. Aspárrena sacó a relucir que, según un inventario de 1852, habian pasado sobre la referida casa censos por valor de

(21) A.M.Z., Actas de 28 de enero, de 11 de febrero, de 18 de junio y de 1 de julio de 1894.

(22) A.H.P.A., D. 775, 14.

(23) La separación consistió "en la apertura de una brecha de 70 pies de ancho de modo que cada una de las dos porciones quedasen claramente delimitadas. Del proceso y tramitación del expediente sobre la división del arbolado se levantó escritura pública el 24 de julio de 1862 por Martin Echevarria, escribano público de Salvatierra. J. Mosquera, 1968, en su trabajo sobre ordenación de la sierra de Encia en relación al tema, afirmaba desconocer la fecha, en que se había abierto la brecha, que dividió en dos partes el trozo, asignado en 1859 a las Hermandades de Aspárrena y San Millán. Con los datos, que se han encontrado en el A.M.Z., se resuelve la laguna informativa comentada en torno a la división del arbolado de Encía.

(24) A.H.P.A., D. 775, 14.

(25) A.M.Z., Acta de 28 de enero de 1894. 
27.500 reales sin que Zalduondo hubiese participado en su redención, obligando de este modo a Zalduondo a la presentación de documentos, que acreditasen la legitimidad de los derechos, que le asistian en relación a la Casa Consistorial. El asunto quedó asi y constituye un interesante antecedente de lo que, en años posteriores, ocurrió.

Hacia 1909, se estaba construyendo la carretera que, de Araya, pasando por Zalduondo, se dirige a Galarreta. La carretera "era de verdadera necesidad para los intereses de la villa y sus vecinos pues, por ella, se podrá dar salida a los productos que al presente es costosísimo y aun imposible en la temporada de lluvias por los caminos que existen"; sin embargo, el municipio no contaba con fondos "para atender a los gastos que ha de originar su construcción ni con medios para poderla arbitrar puesto que sus montes no están en condiciones de extraer recursos forestales ni tampoco puede aumentarse los repartos vecinales por ser ya bastante sabicos" (26). Ayuntamiento y Junta Municipal, para salir del apuro, acordaron vender la participación, que el municipio tenía en la casa consistorial del Ayuntamiento de Aspárrena y en el arbolado de la Parzonería General de Guipúzcoa y Alava, en el de Encía y en el de la Comunidad de Ubarrundia.

Por escritura expedida por el notario Adolfo Carrasco, en Salvatierra a 11 de diciembre de 1909, Zalduondo vendió al Ayuntamiento de Aspárrena el arbolado, que le correspondía en Alzania, Olza y Urbía, en Encía y en Ubarrundia, reservándose el derecho de propiedad sobre el suelo de los montes expresados, así como la parte que poseía en la casa consistorial del Ayuntamiento de la Hermandad de Aspárrena, sita en Araya (27). Tasados estos bienes por técnicos de la Diputación en 52.105 pesetas (28), se convino por ambas partes en que, a Zalduondo, se le debian 4.750 pesetas, a las que, si se añaden los gastos de escrituración que corrian por cuenta de Aspárrena, vendrian a alcanzar alrededor del $10 \%$ del valor total tasado, porcentaje de reparto que, desde 1909, vino a sustituir lo estipulado sobre este punto en el convenio de 1765.

Entre las cláusulas de la escritura de venta, resulta de interés resaltar la quinta, que salvaguardó, previa autorización y señalamiento del Ayuntamiento de Aspárrena, los derechos de los pastores de Zalduondo a cortar el material y la leña, que necesiten "para sus hogares y construcción de chozas y carracas para su refugio y el de sus ganados" (29).

(26) Véase, además de la escritura (A.M.Z.), el acta de 15 de noviembre de 1909 (A.M.Z., Actas).

(27) El acuerdo de venta fue tomado en la sesión celebrada el 10 de diciembre de 1909 (A.M.Z., Actas).

(28) Para el asunto de la tasación de los bienes, consúltese el acta de 5 de septiembre de 1909 y el expediente D. $4303 / 20$ del A.H.P.A.

(29) A.M.Z. 
La venta, por parte de Zalduondo, de su participación en el vuelo de Alzania, Olza y Urbía, de Encía y de Ubarrundia, como fórmula para allegar fondos, con los que cubrir sus necesidades económicas, no es un caso excepcional en estos montes $y$, ya anteriormente, fue utilizada para idénticos fines por Salvatierra con la venta de sus participaciones en suelo y en vuelo en Ubarrundia y en la Parzoneria General de Guipúzcoa y Alava (30). En el caso de Zalduondo, la venta tampoco era ajena a las dificultades/utilidades que estos montes le entrañaban. Sin muchos medios, entre los que escoger y ante una obra de evidente necesidad, la elección del vuelo de los montes de Alzania, Olza y Urbia, de Encía y de Ubarrundia vino facilitada porque los mismos "apenas reportaban al presente recursos ni ventajas, no siendo los pastos para sus ganados" (31). La percepción de ingresos líquidos en concepto de aprovechamientos madereros escapaba de su control, que estaba en manos del Ayuntamiento de la Hermandad de Aspárrena, mientras que, independientemente de producirse la rendición anual de cuentas por parte de Aspárrena en relación a los bienes mancomunados de la Hermandad y de la percepción de beneficios, nada ni nadie se oponía a que el vecindario echase sus ganados a los pastos, solucionando así los problemas estacionales originados en la alimentación de los mismos.

\section{RENDICION ANUAL DE CUENTAS POR INGRESOS PROVENIEN- TES DE LOS BIENES PATRIMONIALES DE LA ANTIGUA HERMAN- DAD.}

La disolución de la Hermandad supuso un vacío institucional pues, con ella, se produjo la desaparición del encajamiento organizativo de los diferentes integrantes que la componian, en relación a las vías de representación y participación en la toma de decisiones en los asuntos referentes a los bienes procomunales de la Hermandad.

La disolución no vino acompañada de una separación de bienes. En un primer momento, la vía de salida escogida para resolver la situación originada a partir de la desintegración de la Hermandad y permanencia de la mancomunidad en cuanto a los bienes patrimoniales de la misma presentó unos canales anclados en la situación anterior a la disolución, vehiculándose a través de la figura del Procurador

(30) En 1849, las Hermandades de Aspárrena y San Millán pretendieron vender sus derechos sobre el arbolado de Alzania, Qlza y Urbia pero, ante la oposición de los vecindarios de los pueblos integrantes en la misma, el proyecto no prosperó a pesar de estar aprobado en Junta (A.H.P.A., D. 740/18).

(31) A.H.P.A., D. 4303, 20. 
Sindico General y del turno quinquenal de acceso al mismo según la distribución en cuadrillas de los pueblos integrantes de la Hermandad a efectos de reparto de cargos. La situación creada se distinguía por unos matices totalmente distintos a la situación anterior y se terminó abandonando las fórmulas ensayadas durante el período de vigencia de la Hermandad.

La participación con personalidad propia en las reuniones de las Juntas de las Parzonerias constituyó una posible alternativa a la situación creada con la desintegración de la Hermandad y tuvo su concreción práctica en la Parzonería General de Encía en el período 1906-1920. Por propia iniciativa de Zalduondo, la cota de presencia institucional en la organización de las Juntas de Parzonería se suprimió y esta vía, sino muerta, ha quedado en cierto modo abandonada.

Desde 1859, la vertebración institucional entre los municipios de Aspárrena y Zalduondo por cuestión de los bienes patrimoniales se canalizó a través de la representación y presencia en las Juntas de la Parzoneria General de Guipúzcoa y Alava por parte del municipio de Aspárrena y del descargo y de la rendición de cuentas de aquél ante Zalduondo, la otra parte congozante de los bienes de la Hermandad.

La rendición de cuentas, por costumbre, estaba marcada que fuera anual. Así, se conocen balances de cuentas en años sucesivos para $1869,1870,1871$ y 1872 , para 1878 y 1879 , para 1882,1883 y 1884 , para 1926, 1927 y 1928. Probablemente, al no producirse beneficios líquidos, la costumbre se saltó en algunos años: así desde 1872, no se celebró el acto de rendición de cuentas hasta 1876 y, desde 1879, no volvió a repetirse el hecho hasta 1882.

Desde 1885 hasta 1899, año en el que, en un trece de junio, se revisaron las cuentas de los años de 1885 hasta 1897 , las dos partes no se volvieron a reunir para proceder a analizar la situación de las cuentas correspondientes a los bienes procomunales de la Hermandad. En este retraso, influyeron factores varios: el importante déficit de la cuenta de 1885, cuestiones personales y la inhibición del municipio de Aspárrena.

La cuenta del año de 1885 dió un déficit de $1386,76 \mathrm{cs}$. y en tanto que no hubiera ingresos, Zalduondo desatendió las citaciones, según costumbre, verbales para celebrar la rendición de cuentas. Cuando los ingresos endosaron el déficit de 1885, lográndose beneficios, Aspárrena se inhibió y no cursó las acostumbradas citaciones (32), y,

(32) A.M.Z., Actas de 10 de abril de 1892, de 18 de mayo y 1 de julio de 1894, de 7 de abril de 1895 y de 3 de junio de 1898. En todas las actas citadas, los corporativos debaten sobre el tema de la convocatoria de rendición de cuentas. 
aunque la Diputación Provincial, por decreto de 20 de febrero de 1895, ordenó a Aspárrena que, con la mayor brevedad posible convocase a Zalduondo a la liquidación anual de cuentas, la convocatoria tardó más de dos años en llegar, en concreto, hasta el 4 de junio de 1898 (33).

La intervención, en el retraso, de elementos personales viene amparada en el descargo, que el municipio de Aspárrena efectuó para explicar el retraso en las cuentas y suspensión de la reunión de 31 de mayo de 1894, achacándolo, sin especificarse nombre $y$ apellidos, a los manejos de la persona encargada de confeccionar la liquidación anual de las cuentas referentes a los bienes patrimoniales (34).

Tras el largo plazo transcurrido sin reunirse para proceder al descargo de cuentas y en un momento de roces intercomunitarios, era lógico que surgiesen protestas a partidas de las cuentas presentadas y, asi sucedió, al menos, con tres de ellas, que los representantes de Zalduondo interpretaban que no les incumbia pagar (35). Lo anterior dificultó la aprobación y liquidación de cuentas, que se retrasó al 13 de julio de 1899, un año después de que Aspárrena y Zalduondo, con tal fin, celebrasen la primera reunión.

Desde 1899, el plazo en la rendición de cuentas deja de ser anual y los períodos entre dos rendiciones de cuentas se alargaron cada vez más. En ello, influyeron la presencia de Zalduondo en la Junta de la Parzoneria General de Encia y, en especial, la reducción en la participación de Zalduondo en los ingresos y en los bienes procomunales de la Hermandad que, a partir de 1906, consistian en los derechos sobre los aprovechamientos del suelo en los montes de Alzania, Olza y Urbía, en los de Encía y en los de Ubarrundia. Desde la rendición de cuentas de 1897, se dispone información sobre las celebradas para

(33) A.M.Z., Acta de 3 de junio de 1898.

(34) En el expediente, tramitado a instancia de Zalduondo y resuelto por Decreto de la Diputación de Alava de 20 de febrero de 1895, se recoge información aportada por el Ayuntamiento de Aspárrena del tenor siguiente: "... existe en la Secretaria del Ayuntamiento un borrador de las correspondientes a los años de 1885 y 1886 , hecho por la persona que ha dado lugar a que se interrumpiera la costumbre de liquidar al principio de cada año..." o "el ayuntamiento creyó muy acertada por haber venido aquellos acompañados de persona ajena a los municipios $y$ que es el causante de todos estos trabajos ..." (A.M.Z.).

(35) En la cuentas, consta la anotación de "con advertencia" en diversas partidas: así, las 300 pesetas registradas en el año 1889-1890, por reconocimiento de mojones del municipio y del Ayuntamiento. A estas partidas, debe referirse el acta de 12 de junio de 1898 cuando transmite la información dada por los comisionados nombrados con tal motivo: “...se hallan varias partidas de las incluidas en las cuentas de referencia que ni en mucho son de incumbencia de este municipio (A.M.Z.). 
los años 1926-1927 (36), 1928 (37) y 1952, año, en el que se revisaron las cuentas correspondientes a los años 1939-1952 tras reclamación planteada a Aspárrena por Zalduondo.

\section{CONCLUSIONES}

La disolución de la Hermandad motivada en buena parte por las conflictivas relaciones a las que se vieron abocados en la transición del siglo XVIII al XIX las dos partes diferenciadas que la constituyeron, es decir, Zalduondo, por un lado, y los nueve pueblos restantes, por el otro, dejó planteadas sin resolver, lo que se puede llegar a explicar por la naturaleza y dimensión económica de los bienes comunales a repartir, unas cuestiones, que han sido fuente y semillero de nuevas tensiones y desavenencias intercomunitarias.

La disolución de la Hermandad dejó a Zalduondo al margen de la organización institucional-administrativa de las Parzonerias Generales de Guipúzcoa y de Alava y de Encía. La creación de una Junta de Hermandad encargada de la titularidad de los bienes comunales y de la representación en las Juntas de las Parzonerias, dotada de su corrèspondiente reglamento de funcionamiento, hubiera resuelto la cuestión pero esto no se hizo entonces ni se ha hecho posteriormente.

\section{Abreviaturas utilizadas}
A.H.P.A.- Archivo Histórico Provincial de Alava. Plaza de la Provincia. Vitoria-Gasteiz.
A.M.S.- Archivo Municipal de Salvatierra (Alava). Ayuntamiento.
A.M.Z.- Archivo Municipal de Zalduondo (Alava) Ayuntamiento.
A.M.S.M.- Archivo Municipal de San Millán (Alava). Ayuntamiento Ordoñana.

(36) A.M.Z., Acta de 12 de febrero de 1928.

(37) A.M.Z., Acta de 12 de junio de 1929. 
